\title{
The Relationship Between Cardiovascular Health and Rate of Cognitive Decline in Young-Old and Old-Old Adults: A Population-Based Study
}

\author{
Andreja Speh ${ }^{\mathrm{a}, \mathrm{b}, \mathrm{c}, \mathrm{d}}$, Rui Wang ${ }^{\mathrm{a}, \mathrm{e}, \mathrm{f}}$, Bengt Winblad ${ }^{\mathrm{b}, \mathrm{g}}$, Milica G. Kramberger ${ }^{\mathrm{c}, \mathrm{d}}$, Lars Bäckman ${ }^{\mathrm{a}}$, \\ Chengxuan Qiu ${ }^{\mathrm{a}}$ and Erika J. Laukka ${ }^{\mathrm{a}, \mathrm{h}, *}$ \\ a Aging Research Center, Department of Neurobiology, Care Sciences and Society, Karolinska Institutet and \\ Stockholm University, Solna, Sweden \\ ${ }^{\mathrm{b}}$ Division of Neurogeriatrics, Department of Neurobiology, Care Sciences and Society, Karolinska Institutet, \\ Solna, Sweden \\ ${ }^{\mathrm{c}}$ Department of Neurology, University Medical Center Ljubljana, Ljubljana, Slovenia \\ ${ }^{\mathrm{d}}$ Medical Faculty, University of Ljubljana, Ljubljana, Slovenia \\ ${ }^{\mathrm{e}}$ The Swedish School of Sport and Health Science, GIH, Stockholm, Sweden \\ ${ }^{\mathrm{f}}$ Wisconsin Alzheimer's Disease Research Center, University of Wisconsin School of Medicine and Public Health, \\ Madison, WI, USA \\ ${ }^{\mathrm{g}}$ Theme Inflammation and Aging, Karolinska University Hospital, Huddinge, Sweden \\ ${ }^{\mathrm{h}}$ Stockholm Gerontology Research Center, Stockholm, Sweden
}

Accepted 16 September 2021

Pre-press 19 October 2021

\begin{abstract}
.
Background: Modifiable vascular risk factors have been associated with late-life cognitive impairment. The Life Simple 7 (LS7) score comprises seven cardiovascular health metrics: smoking, diet, physical activity, body mass index, plasma glucose, total serum cholesterol, and blood pressure.

Objective: To investigate the association between individual and composite LS7 metrics and rate of cognitive decline, and potential differences in these associations between young-old and old-old individuals.

Methods: This cohort study included 1,950 participants aged $\geq 60$ years $(M=70.7$ years) from the Swedish National Study on Aging and Care-Kungsholmen (SNAC-K), who underwent repeated neuropsychological testing (episodic and semantic memory, verbal fluency, processing speed, global cognition) across 12 years. The LS7 score was assessed at baseline and categorized as poor, intermediate, or optimal. Level and change in cognitive performance as a function of LS7 categories were estimated using linear mixed-effects models.

Results: Having an optimal LS7 total score was associated with better performance (expressed in standard deviation units) at baseline for perceptual speed $(\beta=0.21,95 \%$ CI $0.12-0.29)$, verbal fluency $(\beta=0.08,0.00-0.16)$, and global cognition ( $\beta=0.06,0.00-0.12)$ compared to the poor group. Age-stratified analyses revealed associations for cognitive level and change only in the young-old ( $<78$ years) group. For the specific metrics, diverging patterns were observed for young-old and old-old individuals.
\end{abstract}

\footnotetext{
${ }^{*}$ Correspondence to: Erika J. Laukka, PhD, Aging Research Center, Karolinska Institutet, Tomtebodavägen 18A, SE-171 65
}

Solna, Sweden. Tel.: +46 8 52485831; E-mail: Erika.Jonsson.Lau kka@ki.se. 
Conclusion: Meeting the LS7 criteria for ideal cardiovascular health in younger old age is associated with slower rate of cognitive decline. However, the LS7 criteria may have a different meaning for cognitive function in very old adults.

Keywords: Aging, cardiovascular risk factors, cognition, epidemiology

\section{INTRODUCTION}

Vascular risk factors play an important role in the development of cognitive impairment and dementia $[1,2]$. In addition, several modifiable risk factors, such as diabetes [3, 4], poor nutrition [5], smoking [6], low physical activity [7], and elevated blood pressure $[8,9]$ have been associated with lower level of cognitive performance and faster rate of cognitive decline. The concurrent presence of several vascular risk factors may exacerbate the process of age-related cognitive decline [10]. Thus, it is important to investigate the combined effect of multiple cardiovascular health risk factors. Indeed, these risk factors rarely occur in isolation and the prevalence of multimorbidity increases with advancing age [11].

Prevention strategies that target multiple modifiable risk factors appear to show promising results for reducing the risk for old-age cognitive impairment. Results from the FINGER project in Finland show that a multidomain intervention including diet, exercise, cognitive training, and vascular risk monitoring may improve or maintain cognitive functioning of non-demented elderly people with increased cardiovascular risk [12]. Thus, it is conceivable that having an optimal cardiovascular health profile may have a favorable influence on age-related cognitive decline in the general population.

The American Heart Association (AHA) has defined a metric of optimal, or ideal, cardiovascular health, also referred to as Life's Simple 7 (LS7), composed of 7 modifiable risk factors for cardiovascular disease [13]. This metric involves four health behaviors (smoking, diet, physical activity, body mass index (BMI)) and three biological health factors (plasma glucose, serum total cholesterol, blood pressure). It categorizes individuals' cardiovascular health as poor, intermediate, or optimal. Distinguishing features of LS7, in comparison to other cardiovascular risk scores, are that it focuses on positive health behaviors and that age is not included in the score. The LS7 was initially designed for adults aged 18 years and older. Hence, the question remains whether the associations between LS7 and cognitive health vary across age groups.
Previous research suggests higher importance of the smoking, glucose, and blood pressure metrics in predicting cognitive decline $[14,15]$; however, the relationships with specific metrics warrant further investigation, especially among older adults. Further, more research is needed to clarify the association between LS7 and rate of cognitive decline in specific domains.

We investigated the relationship of individual and composite LS7 cardiovascular health metrics to baseline performance and rate of change in different cognitive domains (episodic memory, semantic memory, verbal fluency, processing speed, and global cognition). An additional objective was to examine potential differences in these associations for youngold ( $<78$ years) and old-old ( $\geq 78$ years) individuals.

\section{MATERIALS AND METHODS}

\section{Participants}

Participants were from the population-based Swedish National Study on Aging and Care in Kungsholmen (SNAC-K). The original SNAC-K population consisted of 4,590 alive and eligible persons who were $\geq 60$ years old and lived on the island of Kungsholmen in central Stockholm, Sweden. They were randomly selected to take part in the study based on population registries and belonged to 11 pre-specified age cohorts: $60,66,72,78,81,84,87,90,93,96$, and 99 years and older. Between 2001 and 2004, 3,363 persons accepted to participate in the baseline examination consisting of three parts: a nurse interview, a medical examination, and a neuropsychological testing session. Altogether, the examination took about $6 \mathrm{~h}$. The participants are re-examined each time they reach the age of the next cohort. All parts of SNAC-K have been approved by the Ethics Committee at Karolinska Institutet or by the Regional Ethical Review Board in Stockholm, Sweden. All participants provided written informed consent.

After excluding participants with prevalent dementia (DSM IV criteria, $n=321$ ), Parkinson's disease (CERAD criteria, $n=24)$, schizophrenia $(n=13)$, 
Table 1

Definitions of Life Simple 7 score metrics (adapted from Sabia et al. [16])

\begin{tabular}{|c|c|c|c|}
\hline Metric & Poor (score, 0 ) & Intermediate (score, 1) & Optimal (score, 2) \\
\hline Smoking & Current smoker & Stopped in the last 5 years & $\begin{array}{l}\text { Never smoked or stopped }>5 \text { year } \\
\text { ago }\end{array}$ \\
\hline Diet & $\begin{array}{l}\text { Consumption of fruit and vegetables } \\
<2 \text { times per day AND no } \\
\text { consumption of high fiber bread }\end{array}$ & $\begin{array}{l}\text { Consumption of fruit and vegetables } \\
\geq 2 \text { times per day OR } \\
\text { consumption of high fiber bread }\end{array}$ & $\begin{array}{l}\text { Consumption of fruit and vegetables } \\
\geq 2 \text { times per day AND } \\
\text { consumption of high fiber bread }\end{array}$ \\
\hline Physical activity & $\begin{array}{l}\text { Never, }<2-3 \text { times per month, } 2-3 \\
\text { times per month in light and/or } \\
\text { moderate/intense exercise }\end{array}$ & $\begin{array}{l}\text { Light exercise several times per } \\
\text { week or every day }\end{array}$ & $\begin{array}{l}\text { Moderate/intense exercise several } \\
\text { times per week or every day }\end{array}$ \\
\hline Body mass index & $\geq 30 \mathrm{~kg} / \mathrm{m}^{2}$ & $25-29.9 \mathrm{~kg} / \mathrm{m}^{2}$ & $<25 \mathrm{~kg} / \mathrm{m}^{2}$ \\
\hline Plasma glucose & $\begin{array}{l}\mathrm{HbA} 1 \mathrm{c} \geq 6.5 \% \text { OR self-reported } \\
\text { medical history, hypoglycemic } \\
\text { drug use, or diagnosis in the NPR }\end{array}$ & HbA1c $5.7-6.5 \%$ and no diabetes & $\mathrm{HbA} 1 \mathrm{c}<5.7 \%$ \\
\hline $\begin{array}{l}\text { Total serum } \\
\text { cholesterol }\end{array}$ & $\geq 240 \mathrm{mg} / \mathrm{dl}$ & $\begin{array}{l}<200 \mathrm{mg} / \mathrm{dl} \text { treated OR } \\
\quad 200-239 \mathrm{mg} / \mathrm{dl}\end{array}$ & $<200 \mathrm{mg} / \mathrm{dl}$ untreated \\
\hline $\begin{array}{l}\text { Systolic and diastolic } \\
\text { blood pressure }\end{array}$ & $\begin{array}{l}\mathrm{SBP} \geq 140 \mathrm{~mm} \mathrm{Hg} \text { OR DBP } \\
\quad \geq 90 \mathrm{~mm} \mathrm{Hg}\end{array}$ & $\begin{array}{l}\mathrm{SBP}<120 \mathrm{~mm} \mathrm{Hg} \text { and DBP } \\
<80 \mathrm{~mm} \mathrm{Hg} \text { treated OR SBP } \\
120-139 \text { OR DBP } 80-89 \mathrm{~mm} \mathrm{Hg}\end{array}$ & $\begin{array}{l}\mathrm{SBP}<120 \mathrm{~mm} \mathrm{Hg} \text { and } \\
\mathrm{DBP}<80 \mathrm{~mm} \mathrm{Hg} \text { untreated }\end{array}$ \\
\hline
\end{tabular}

HbA1c, glycated hemoglobin; NPR, National Patient Register; SBP, systolic blood pressure; DBP, diastolic blood pressure.

developmental disorder $(n=3)$, history of stroke ( $n=165)$, insufficient data to compute the LS7 score $(n=778)$, and missing cognitive data $(n=109)$, the study sample included 1,950 individuals $(M=70.7$ years, $\mathrm{SD}=9.1$ ). Due to the study design, not all ages were represented in the SNAC-K sample. We categorized those aged 60 to 72 years $(M=65.4, \mathrm{SD}=4.8$, $n=1336$ ) at baseline into a young-old group and those 78 years or older $(M=82.2, \mathrm{SD}=4.4, n=614)$ into an old-old group. For flow chart of study participation, see Supplementary Figure 1.

Compared to our final sample, the excluded participants $(n=1,413)$ were older, had a higher proportion of women, lower education, and lower baseline Mini-Mental State Examination (MMSE) scores $(p<0.001)$.

\section{Life Simple 7 score}

We used data from baseline to extract information on seven cardiovascular health metrics. For each metric, participants were categorized into a poor, intermediate, or optimal cardiovascular health group. We followed the cut-off values used by Sabia et al. [16], with some minor changes for the glucose metric. The cut-off values for all metrics are presented in Table 1.

Smoking status (current/quit/never) and the year of smoking cessation were assessed during the nurse interview.

For diet, data from a 98-item semi-quantitative food frequency questionnaire were used. Average frequencies of intakes over the last year were obtained for each food item on a 9-point scale, ranging from never to $\geq 4$ times per day [17]. We combined all vegetables, fruits, and high-fiber bread into separate variables that were used to categorize the participants.

A questionnaire was also used to collect information on physical activity. Participants reported the frequency of engagement in light (e.g., walking along roads or in parks, short bicycle rides) and moderate to intense (e.g., jogging, high-intensity aerobics) exercise. For those with missing values, participants who used a wheelchair $(n=29)$, could not move indoors or outdoors on their own $(n=16)$, or were unable to walk $50 \mathrm{~m}(n=35)$, were categorized into the poor group.

Body mass index (BMI) was calculated as weight in kilograms divided by squared height in meter. In cases where measured weight or height were missing $(<16 \%$ or the observations), self-reported values were used to calculate BMI.

For plasma glucose, glycated hemoglobin (HbA1c) level was measured using the Swedish MonoS High Performance Liquid Chromatography. To equate it to international values, $1.1 \%$ was added to the $\mathrm{HbA1C}$ value. Diabetes was ascertained on the basis of self-reported medical history, hypoglycemic drug use, diagnosis in the Swedish National Patient Register (NPR: ICD-10 code E11), or HbA1c $\geq 6.5 \%$ ( $48 \mathrm{mmol} / \mathrm{mol})$. Those with no diabetes but with $\mathrm{HbA} 1 \mathrm{c} 5.7-6.5 \%$ (39-48 $\mathrm{mmol} / \mathrm{mol})$ were categorized as having prediabetes [3]. We used the categorization of diabetes, pre-diabetes, and diabetesfree participants to classify individuals into poor, intermediate, and optimal groups. 
Total serum cholesterol was initially measured non-fasting for most participants. If the cholesterol level was $\geq 6.5 \mathrm{mmol} / \mathrm{l}$, participants came for a second measurement, this time fasting. In these cases, the mean of both measurements was used. The cholesterol levels were multiplied by 38.67 [18] in order to obtain the measurement units [mg/dl] used for group classification [16].

Arterial blood pressure was measured twice at a 5-min interval on the left arm in sitting position with a sphygmomanometer and the mean of the two readings was used. Hypertensive medication use was assessed during the medical examination.

After categorizing the metrics into three levels: optimal (score, 2), intermediate (1), and poor (0), we used the sum of all seven metrics to calculate the total score, ranging from 0 to 14 . On the basis of tertiles [19], the total score was further categorized into optimal (9-14), intermediate (7-8), and poor (0-6). Those who had missing values on only one of the seven metrics were added to the sample, if they could be clearly assigned to a LS7 group. That is, those with values $0-4$ were included in the poor group; even if they would have gained the maximum of two additional points for the metric with missing data, this would not change their group classification. Similarly, those with values 9-12 and one missing value were included in the optimal group.

\section{Neuropsychological assessment}

Cognitive performance was assessed at each time point according to standardized procedures [20]. Assessment of episodic memory included free recall of a 16-item word list and a 32-item yes/no word recognition test [21]. Semantic memory was assessed with a 30-item vocabulary task, where participants were instructed to underline the word representing the synonym of each target word [22]. Verbal fluency was assessed with both letter ("A" and "F") and category ("animals" and "professions") fluency [23]. Two tasks of perceptual speed were administered. Digit cancellation [24] required participants to sequentially go through rows of random digits ranging from 1 to 9 and to cross out every "4" they encountered. For pattern comparison [25], participants were asked to go through line-segmented patterns and mark whether the patterns were "same" or "different".

The cognitive test scores were standardized into z-scores according to their baseline mean and standard deviation. The standardized scores were used to create composite scores for each cognitive domain by calculating the mean score when more than one test was available. For participants with data on at least 3 domains, a composite that represents global cognition was computed by taking the average of all available scores.

Participants were followed for an average of 9.4 years $(\mathrm{SD}=3.0)$ with a mean of $1.6(\mathrm{SD}=1.1)$ followup assessments. All participants had data for baseline and $376(19.3 \%)$ participated in 1, $803(41.2 \%)$ in 2, $253(13.0 \%)$ in 3, and $110(5.6 \%)$ in 4 follow-up assessments in addition to the baseline examination.

\section{Vascular diseases}

History of stroke was ascertained on the basis of the stroke-diagnosis status from the National Patient Register (NPR) and included hemorrhagic (ICD-10:160-162; ICD-9 and ICD-8:430-432) and ischemic (ICD-10:163-164; ICD-9 and ICD8:433-434) stroke. History of cardiovascular disease was based on the diagnoses in the NPR, the clinical examination, electrocardiogram, and medication use. It included atrial fibrillation (ICD-10, code I48), heart failure (ICD-10, codes I110, I130, I132, I27, I280, I42, I43; I50, I515, I517, I528, Z941, Z943), and ischemic heart disease (ICD-10, codes I20-22, I24-25, Z951, Z955) [26, 27].

\section{Statistical analysis}

Group differences were determined using chisquare tests for dichotomous variables and ANOVAs for continuous variables. The association between LS7 and level at baseline (intercept) and rate of change in different cognitive domains was estimated using linear mixed models. Follow-up time (years from baseline) was used as the time scale. Fixed effects included LS7 groups (poor, intermediate, optimal), time in study, and an interaction term for the grouping variable and time. Random intercept and slope were estimated as the random part in the mixed effect model. We used unstructured variancecovariance matrices for all models. All analyses controlled for sex, as well as age at baseline and years of education, centered at the sample mean.

\section{RESULTS}

Baseline characteristics of participants in the total sample and the two age groups are displayed in Table 2. Those with a better LS7 score had received more education and were less likely to have a history 


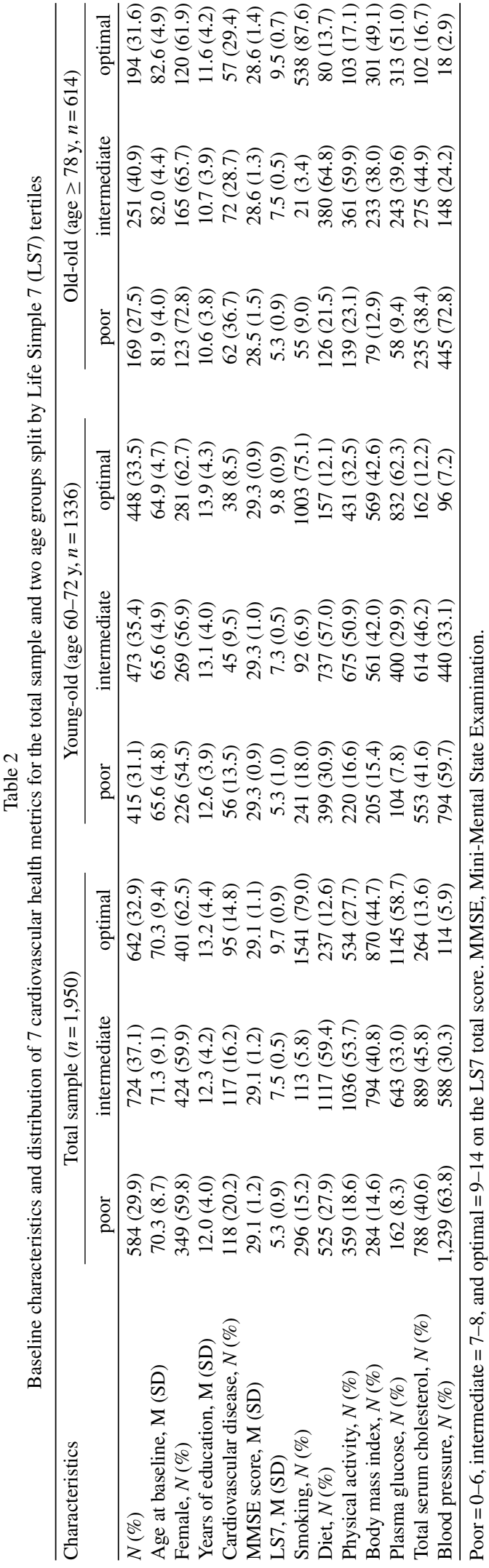

of cardiovascular disease. In addition, in the youngold group, those scoring higher on LS7 were more likely to be female.

The mean for the total LS7 score was 7.6 $(\mathrm{SD}=1.9)$ and the range was 1-13; thus, there were no participants with either a minimum (0) or maximum (14) number of points. On average, participants had 2.4 $(\mathrm{SD}=1.1)$ metrics at an optimal level. The distributions for the individual metrics are displayed in Table 2. The metric with the largest proportion of participants in the optimal group was smoking (79.0\%), followed by plasma glucose (58.7\%). Blood pressure was the metric with the smallest proportion of participants in the optimal group (5.9\%). There were statistically significant differences in the distributions with regard to the two age groups for all metrics. There was a higher percentage of young-old individuals in the optimal LS7 group for blood pressure, physical activity, and glucose. In contrast, old-old individuals were more likely to have optimal levels of BMI, smoking, diet, and cholesterol $(p<0.05)$. In general, these differences were apparent for the comparison between "optimal versus poor" and "optimal versus intermediate", but not for the "intermediate vs. poor" group comparison (data not shown).

\section{Total LS7 score}

Results from the linear mixed models by LS7 tertiles are presented in Table 3. Overall, the results indicate a positive association between LS7 group and cognition for the total sample. Better baseline LS7 was associated with significantly better performance in perceptual speed (intermediate versus poor and optimal versus poor), where persons in the optimal group performed on average $0.21 \mathrm{SD}$ units better at baseline compared to those in the poor group. Less pronounced, although significant effects, were observed for verbal fluency and global cognition (optimal versus poor).

There was a significant interaction between age and LS7 group with regard to performance level for perceptual speed $(p=0.04$ for intermediate versus poor and $p=0.02$ for optimal versus poor) and rate of change in episodic memory $(p=0.02$ for optimal versus poor) and global cognition $(p=0.02$ for optimal versus poor). Therefore, we repeated the analysis in age-stratified groups. The old-old generally exhibited poorer cognitive performance and faster decline in comparison to the young-old. However, the association between LS7 and cognition was more pronounced in the young-old than in the 
Table 3

Estimates from linear mixed models by LS7 tertiles for the total sample $(n=1,950)$, young-old $(n=1,336)$, and old-old $(n=614)$. Beta coefficients together with $95 \%$ confidence intervals represent mean baseline performance and rate of decline for the poor group. For the intermediate and optimal group, coefficients represent intercept differences and differences in rate of change compared to the poor group

\begin{tabular}{|c|c|c|c|c|c|c|}
\hline & & Episodic memory & Semantic memory & Verbal fluency & Perceptual speed & Global cognition \\
\hline \multicolumn{7}{|l|}{ Total sample } \\
\hline \multirow[t]{2}{*}{ poor } & level & $-0.15[-0.23,-0.08]$ & $-0.06[-0.18,-0.04]$ & $-0.11[-0.18,-0.04]$ & $-0.18[-0.25,-0.11]$ & $-0.12[-0.17,-0.07]$ \\
\hline & change & $-0.04[-0.05,-0.03]$ & $-0.03[-0.04,-0.02]$ & $-0.04[-0.04,-0.03]$ & $-0.06[-0.06,-0.05]$ & $-0.04[-0.05,-0.04]$ \\
\hline \multirow[t]{2}{*}{ intermediate } & level & $-0.03[-0.12,0.05]$ & $0.03[-0.07,0.13]$ & $0.06[-0.02,0.14]$ & $0.13[0.05,0.21]^{* *}$ & $0.04[-0.02,0.10]$ \\
\hline & change & $0.01[0.00,0.02]$ & $-0.01[-0.01,0.00]$ & $0.00[0.00,0.01]$ & $0.00[-0.01,0.01]$ & $0.00[-0.01,0.01]$ \\
\hline \multirow[t]{2}{*}{ optimal } & level & $-0.02[-0.11,0.07]$ & $-0.02[-0.12,0.09]$ & $0.08[0.00,0.16]^{*}$ & $0.21[0.12,0.29]^{* * *}$ & $0.06[0.00,0.12]^{*}$ \\
\hline & change & & & & $0.00[-0.01,0.01]$ & $0.01[0.00,0.01]$ \\
\hline \multicolumn{7}{|c|}{ Young-old (60-72 y) } \\
\hline \multirow[t]{2}{*}{ poor } & level & $-0.15[-0.24,-0.06]$ & $-0.10[-0.22,-0.05]$ & $-0.13[-0.22,-0.05]$ & $-0.21[-0.30,-0.13]$ & $-0.15[-0.21,-0.08]$ \\
\hline & change & $-0.04[-0.05,-0.03]$ & $-0.02[-0.03,-0.02]$ & $-0.03[-0.04,-0.02]$ & $-0.06[-0.06,-0.05]$ & $-0.04[-0.04,-0.03]$ \\
\hline \multirow[t]{2}{*}{ intermediate } & level & $-0.02[-0.13,0.08]$ & $0.08[-0.04,0.21]$ & $0.09[-0.01,0.19]$ & $0.20[0.10,0.30]^{* * *}$ & $0.08[0.01,0.16]^{*}$ \\
\hline & change & & & $0.01[0.00,0.01]$ & $0.00[-0.01,0.01]$ & $0.01[0.00,0.01]$ \\
\hline \multirow[t]{2}{*}{ optimal } & level & $-0.04[-0.15,0.07]$ & $0.02[-0.10,0.15]$ & $0.14[0.04,0.24]^{* *}$ & $0.30[0.20,0.41]^{* * *}$ & $0.10[0.03,0.18]^{* *}$ \\
\hline & change & $0.01[0.00,0.03]^{*}$ & $0.01[0.00,0.02]$ & $0.00[0.00,0.01]$ & $0.00[-0.01,0.01]$ & $0.01[0.00,0.02]^{*}$ \\
\hline \multicolumn{7}{|l|}{ Old-old ( $\geq 78 \mathrm{y}$ ) } \\
\hline \multirow[t]{2}{*}{ poor } & level & $-0.16[-0.31,-0.01]$ & $0.00[-0.19,0.09]$ & $-0.05[-0.19,0.09]$ & $-0.11[-0.28,0.05]$ & $-0.07[-0.18,0.04]$ \\
\hline & change & $-0.06[-0.08,-0.04]$ & $-0.06[-0.07,-0.04]$ & $-0.08[-0.09,-0.06]$ & $-0.09[-0.11,-0.07]$ & $-0.07[-0.09,-0.06]$ \\
\hline \multirow[t]{2}{*}{ intermediate } & level & $-0.06[-0.21,0.10]$ & $-0.06[-0.24,0.11]$ & $-0.02[-0.16,0.13]$ & $0.00[-0.16,0.17]$ & $-0.03[-0.15,0.08]$ \\
\hline & change & & & & $-0.01[-0.04,0.01]$ & $-0.01[-0.03,0.01]$ \\
\hline \multirow[t]{2}{*}{ optimal } & level & $0.04[-0.13,0.21]$ & $-0.08[-0.27,0.10]$ & $-0.03[-0.19,0.12]$ & $0.07[-0.11,0.25]$ & $0.00[-0.12,0.12]$ \\
\hline & change & $-0.02[-0.05,0.01]$ & $0.00[-0.03,0.03]$ & $0.00[-0.02,0.02]$ & $-0.02[-0.04,0.01]$ & $-0.01[-0.03,0.01]$ \\
\hline
\end{tabular}

${ }^{*} p<0.05,{ }^{* *} p<0.01,{ }^{* * *} p<0.001$. Adjusted for sex, age, and education.

old-old. We observed significant positive associations between LS7 and level of performance for verbal fluency, perceptual speed, and global cognition in the young-old. Furthermore, a higher LS7 score was associated with slower decline in episodic memory and global cognition in this age group, where persons in the optimal group exhibited on average 0.01 SD units/year slower decline compared to those in the poor group. No statistically significant results were found neither for level nor for rate of change in the old-old group (see Table 3).

We also tested for potential interaction effects between sex and LS7 group. One significant effect was observed with regard to performance level for verbal fluency ( $p=0.038$ for optimal versus poor). Stratified analyses showed that the beneficial effect of being in the optimal group was present only for men $(p<0.01)$, whereas no such effect was observed for women $(p=0.72)$. No significant interactions were found for sex and LS7 group with regard to performance change (data not shown).

\section{Individual LS7 metrics}

Results concerning the individual LS7 metrics are displayed in Table 4. The most common finding was a positive association between a higher score and better cognition in the total sample. An exception was total serum cholesterol, where better levels were associated with both lower performance and faster cognitive decline. Somewhat unexpectedly, intermediate levels of smoking and diet were associated with faster semantic memory decline compared to the poor group. In contrast, having an intermediate or optimal blood pressure score was associated with slower decline for all cognitive domains. Similarly, a better plasma glucose score was associated with better performance in verbal fluency and perceptual speed and slower decline in semantic memory, verbal fluency, and global cognition.

We also explored the associations between individual LS7 metrics and cognitive performance for the two age groups (Table 5). In the young-old group, the pattern resembled that of the total sample. The most pronounced associations were observed for glucose, where lower plasma glucose levels were associated with slower decline in all cognitive domains, except of episodic memory, which was borderline significant ( $p=0.07$ for intermediate versus poor and $p=0.08$ for optimal versus poor). In contrast, better total serum cholesterol levels were associated with faster decline in episodic memory and global cognition, similar to what was observed in the total sample. For the old-old, there were fewer significant associations and most often they reflected a negative association between a higher LS7 score and cognition. 
Table 4

Estimates from the linear mixed models by LS7 tertiles for 7 individual metrics for the total sample. Beta coefficients together with $95 \%$ confidence intervals represent mean baseline performance and rate of decline for the poor group. For the intermediate and optimal group, coefficients represent intercept differences and differences in rate of change compared to the poor group

\begin{tabular}{|c|c|c|c|c|}
\hline LS7 metrics & & poor & intermediate & optimal \\
\hline \multicolumn{5}{|l|}{ Smoking $(n=1,950)$} \\
\hline \multirow[t]{2}{*}{ episodic memory } & level & $-0.23[-0.33,-0.13]$ & $-0.06[-0.23,0.12]$ & $0.08[-0.02,0.18]$ \\
\hline & change & $-0.04[-0.06,-0.03]$ & $0.02[0.00,0.05]$ & $0.01[-0.01,0.02]$ \\
\hline \multirow[t]{2}{*}{ semantic memory } & level & $0.01[-0.14,0.04]$ & $0.05[-0.14,0.25]$ & $-0.09[-0.20,0.03]$ \\
\hline & change & $-0.02[-0.03,-0.01]$ & $-0.02[-0.04,0.00]^{*}$ & $-0.01[-0.02,0.01]$ \\
\hline \multirow[t]{2}{*}{ verbal fluency } & level & $-0.05[-0.14,0.04]$ & $0.00[-0.16,0.16]$ & $-0.02[-0.11,0.08]$ \\
\hline & change & $-0.04[-0.04,-0.03]$ & $0.00[-0.01,0.02]$ & $0.00[-0.01,0.01]$ \\
\hline \multirow[t]{2}{*}{ perceptual speed } & level & $-0.26[-0.35,-0.16]$ & $0.11[-0.04,0.27]$ & $0.23[0.14,0.32]^{* * *}$ \\
\hline & change & $-0.06[-0.07,-0.05]$ & $0.01[-0.01,0.03]$ & $0.00[-0.01,0.01]$ \\
\hline \multirow[t]{2}{*}{ global cognition } & level & $-0.12[-0.19,-0.05]$ & $0.04[-0.07,0.16]$ & $0.05[-0.02,0.11]$ \\
\hline & change & $-0.04[-0.05,-0.03]$ & $0.00[-0.01,0.02]$ & $0.00[-0.01,0.01]$ \\
\hline \multicolumn{5}{|l|}{ Diet $(n=1,879)$} \\
\hline \multirow[t]{2}{*}{ episodic memory } & level & $-0.18[-0.25,-0.10]$ & $0.04[-0.04,0.12]$ & $-0.06[-0.18,0.06]$ \\
\hline & change & $-0.03[-0.04,-0.02]$ & $-0.01[-0.02,0.01]$ & $0.00[-0.02,0.01]$ \\
\hline \multirow[t]{2}{*}{ semantic memory } & level & $-0.12[-0.19,-0.05]$ & $0.13[0.04,0.23]^{* *}$ & $0.02[-0.12,0.16]$ \\
\hline & change & $-0.02[-0.03,-0.02]$ & $-0.01[-0.02,0.00]^{*}$ & $-0.01[-0.02,0.01]$ \\
\hline \multirow[t]{2}{*}{ verbal fluency } & level & $-0.12[-0.19,-0.05]$ & $0.10[0.02,0.17]^{*}$ & $0.10[-0.01,0.21]$ \\
\hline & change & $-0.03[-0.04,-0.03]$ & $0.00[-0.01,0.00]$ & $-0.01[-0.02,0.00]$ \\
\hline \multirow[t]{2}{*}{ perceptual speed } & level & $-0.10[-0.17,-0.02]$ & $0.06[-0.01,0.13]$ & $0.02[-0.09,0.13]$ \\
\hline & change & $-0.05[-0.06,-0.04]$ & $-0.01[-0.01,0.00]$ & $0.00[-0.02,0.01]$ \\
\hline \multirow[t]{2}{*}{ global cognition } & level & $-0.12[-0.17,-0.06]$ & $0.08[0.02,0.13]^{* *}$ & $0.01[-0.07,0.09]$ \\
\hline & change & $-0.04[-0.04,-0.03]$ & $-0.01[-0.01,0.00]$ & $0.00[-0.01,0.01]$ \\
\hline \multicolumn{5}{|c|}{ Physical activity $(n=1,929)$} \\
\hline \multirow[t]{2}{*}{ episodic memory } & level & $-0.20[-0.29,-0.11]$ & $0.06[-0.04,0.15]$ & $0.02[-0.09,0.12]$ \\
\hline & change & $-0.04[-0.05,-0.03]$ & $0.00[-0.01,0.01]$ & $0.01[-0.01,0.02]$ \\
\hline \multirow[t]{2}{*}{ semantic memory } & level & $-0.11[-0.28,-0.12]$ & $0.12[0.01,0.23]^{*}$ & $-0.02[-0.14,0.11]$ \\
\hline & change & $-0.03[-0.04,-0.02]$ & $0.00[-0.01,0.01]$ & $0.00[-0.01,0.01]$ \\
\hline \multirow[t]{2}{*}{ verbal fluency } & level & $-0.20[-0.28,-0.12]$ & $0.17[0.08,0.26]^{* * *}$ & $0.18[0.08,0.27]^{* * *}$ \\
\hline & change & $-0.03[-0.04,-0.02]$ & $-0.01[-0.02,0.00]$ & $0.00[-0.01,0.01]$ \\
\hline \multirow[t]{2}{*}{ perceptual speed } & level & $-0.19[-0.27,-0.10]$ & $0.12[0.04,0.21]^{* *}$ & $0.20[0.10,0.30]^{* * *}$ \\
\hline & change & $-0.05[-0.06,-0.04]$ & $-0.01[-0.02,0.00]$ & $0.00[-0.01,0.01]$ \\
\hline \multirow[t]{2}{*}{ global cognition } & level & $-0.17[-0.23,-0.11]$ & $0.12[0.05,0.18]^{* * *}$ & $0.10[0.03,0.17]^{* *}$ \\
\hline & change & $-0.04[-0.05,-0.03]$ & $0.00[-0.01,0.00]$ & $0.00[-0.01,0.01]$ \\
\hline \multicolumn{5}{|c|}{ Body mass index $(n=1,948)$} \\
\hline episodic memory & level & $-0.15[-0.25,-0.05]$ & $-0.01[-0.11,0.10]$ & $-0.04[-0.14,0.07]$ \\
\hline & change & $-0.03[-0.05,-0.02]$ & $0.00[-0.02,0.01]$ & $-0.01[-0.02,0.01]$ \\
\hline semantic memory & level & $-0.11[-0.21,-0.02]$ & $0.08[-0.04,0.21]$ & $0.05[-0.07,0.17]$ \\
\hline & change & $-0.03[-0.04,-0.02]$ & $0.00[-0.01,0.01]$ & $0.01[0.00,0.02]$ \\
\hline verbal fluency & level & $-0.12[-0.21,-0.02]$ & $0.07[-0.02,0.17]$ & $0.05[-0.05,0.15]$ \\
\hline & change & $-0.03[-0.04,-0.03]$ & $0.00[-0.01,0.01]$ & $0.00[-0.01,0.01]$ \\
\hline perceptual speed & level & $-0.18[-0.27,-0.09]$ & $0.14[0.04,0.24]^{* *}$ & $0.12[0.02,0.21]^{*}$ \\
\hline & change & $-0.06[-0.06,-0.05]$ & $0.00[-0.01,0.01]$ & $0.00[-0.01,0.01]$ \\
\hline global cognition & level & $-0.13[-0.20,-0.07]$ & $0.07[0.00,0.15]^{*}$ & $0.04[-0.03,0.12]$ \\
\hline & change & $-0.04[-0.05,-0.03]$ & $0.00[-0.01,0.01]$ & $0.00[-0.01,0.01]$ \\
\hline Plasma glucose $(n=1$ & & & & \\
\hline episodic memory & level & $-0.08[-0.20,0.05]$ & $-0.10[-0.24,0.04]$ & $-0.10[-0.23,0.03]$ \\
\hline & change & $-0.04[-0.06,-0.03]$ & $0.00[-0.02,0.02]$ & $0.01[-0.01,0.03]$ \\
\hline semantic memory & level & $-0.14[-0.28,-0.05]$ & $0.07[-0.08,0.23]$ & $0.11[-0.04,0.26]$ \\
\hline & change & $-0.04[-0.05,-0.03]$ & $0.01[-0.01,0.02]$ & $0.02[0.00,0.03]^{*}$ \\
\hline verbal fluency & level & $-0.17[-0.28,-0.05]$ & $0.14[0.01,0.26]^{*}$ & $0.11[-0.01,0.23]$ \\
\hline & change & $-0.05[-0.06,-0.04]$ & $0.00[-0.01,0.02]$ & $0.02[0.01,0.03]^{* *}$ \\
\hline perceptual speed & level & $-0.23[-0.35,-0.12]$ & $0.17[0.04,0.29]^{* *}$ & $0.20[0.08,0.32]^{* *}$ \\
\hline & change & $-0.06[-0.08,-0.05]$ & $0.00[-0.01,0.02]$ & $0.01[0.00,0.02]$ \\
\hline global cognition & level & $-0.15[-0.23,-0.06]$ & $0.06[-0.03,0.16]$ & $0.08[-0.01,0.17]$ \\
\hline & change & $-0.05[-0.06,-0.04]$ & $0.00[-0.01,0.01]$ & $0.01[0.00,0.02]^{*}$ \\
\hline
\end{tabular}


Table 4

(Continued)

\begin{tabular}{llccc}
\hline LS7 metrics & & poor & intermediate & optimal \\
\hline Total serum cholesterol $(n=1,941)$ & & & \\
episodic memory & level & $-0.17[-0.24,-0.10]$ & $0.01[-0.07,0.08]$ & $-0.02[-0.13,0.09]$ \\
& change & $-0.03[-0.04,-0.03]$ & $-0.01[-0.02,0.00]$ & $-0.01[-0.02,0.01]$ \\
semantic memory & level & $0.01[-0.09,0.04]$ & $-0.11[-0.20,-0.03]^{*}$ & $-0.04[-0.16,0.09]$ \\
& change & $-0.03[-0.03,-0.02]$ & $0.00[-0.01,0.01]$ & $-0.01[-0.02,0.01]$ \\
verbal fluency & level & $-0.02[-0.09,0.04]$ & $-0.07[-0.14,0.00]^{*}$ & $-0.02[-0.12,0.08]$ \\
& change & $-0.03[-0.04,-0.03]$ & $0.00[-0.01,0.00]$ & $-0.01[-0.02,0.00]^{*}$ \\
perceptual speed & level & $-0.05[-0.12,0.01]$ & $-0.01[-0.08,0.06]$ & $-0.04[-0.14,0.06]$ \\
& change & $-0.05[-0.06,-0.05]$ & $-0.01[-0.01,0.00]$ & $-0.01[-0.02,0.00]^{*}$ \\
global cognition & level & $-0.06[-0.11,-0.01]$ & $-0.05[-0.10,0.00]$ & $-0.03[-0.11,0.04]$ \\
& change & $-0.04[-0.04,-0.03]$ & $0.00[-0.01,0.00]$ & $-0.01[-0.02,0.00]^{*}$ \\
Blood pressure $(n=1,941)$ & & & \\
episodic memory & level & $-0.15[-0.21,-0.09]$ & $-0.05[-0.12,0.03]$ & $-0.03[-0.19,0.12]$ \\
& change & $-0.04[-0.05,-0.03]$ & $0.01[0.00,0.02]^{*}$ & $0.00[-0.02,0.02]$ \\
semantic memory & level & $-0.06[-0.11,0.00]$ & $0.03[-0.06,0.12]$ & $-0.02[-0.20,0.15]$ \\
& change & $-0.03[-0.04,-0.03]$ & $0.01[0.00,0.02]^{*}$ & $0.01[0.00,0.03]$ \\
verbal fluency & level & $-0.05[-0.11,0.00]$ & $-0.03[-0.10,0.04]$ & $-0.01[-0.15,0.13]$ \\
& change & $-0.04[-0.04,-0.03]$ & $0.01[0.00,0.02]^{*}$ & $0.01[0.00,0.02]$ \\
perceptual speed & level & $-0.07[-0.13,-0.02]$ & $0.00[-0.07,0.08]$ & $0.07[-0.07,0.21]$ \\
& change & $-0.06[-0.06,-0.05]$ & $0.00[-0.01,0.01]$ & $0.02[0.00,0.03]^{*}$ \\
global cognition & level & $-0.08[-0.12,-0.04]$ & $0.00[-0.06,0.05]$ & $0.01[-0.09,0.11]$ \\
& change & $-0.04[-0.05,-0.04]$ & $0.01[0.00,0.01]^{*}$ & $0.01[0.00,0.02]^{*}$ \\
\hline
\end{tabular}

${ }^{*} p<0.05,{ }^{* *} p<0.01,{ }^{* * *} p<0.001$. Adjusted for sex, age, and education.

The exception was physical activity, where more active individuals tended to have better cognitive performance, and blood pressure, where individuals in the optimal group had better performance on the semantic memory task. By contrast, better levels of BMI, smoking, and plasma glucose were associated with faster cognitive decline.

\section{Supplementary analysis}

Performance for the optimal group was largely similar to that of the intermediate group (data not shown). However, in some instances, the optimal group outperformed the intermediate group $(p=$ 0.045 for perceptual speed performance, $p=0.003$ for semantic memory decline). Also, for individual metrics, performance for the intermediate and optimal groups was generally similar, with the exception of physical activity and plasma glucose, where those in the optimal group outperformed the intermediate group in verbal fluency and global cognitive decline.

After excluding those with a history of cardiovascular disease at baseline $(n=320)$, only the association between the LS7 total score and perceptual speed remained significant in the total sample. However, the associations in the young-old group remained largely the same (Supplementary Table 1). As for individual metrics, the associations between plasma glucose and cognition no longer remained significant (Supplementary Table 2). Again, the pattern of results from the age stratified analyses resembled that of the original sample.

\section{DISCUSSION}

In this prospective cohort study of individuals 60 years and older, a higher LS7 score was overall associated with higher levels of processing speed, verbal fluency, and global cognitive performance. An important finding was that the patterns for younger and older individuals differed. Belonging to the optimal or intermediate LS7 groups was associated with better performance and slower rate of cognitive decline only in young-old participants. Different patterns were also observed depending on which LS7 metric was examined.

None of the participants met optimal criteria on all seven metrics, which is consistent with other studies reporting a prevalence of less than $1 \%$ in the optimal group for all metrics $[14,15,28]$. It is noteworthy that, although increasing age was associated with a numerically lower score, the mean LS7 score $(M=7.5)$ was virtually identical for the young-old and old-old age groups. A similar study targeting middle-aged individuals reported the same mean score as in our sample [19], whereas other studies reported higher means $[15,16]$. This suggests that the cardiovascular health of our sample, especially the older age 
Table 5

Estimates from linear mixed models by LS7 tertiles for 7 individual metrics for the for young-old $(N=1,368)$ and old-old $(N=654)$. Beta coefficients together with $95 \%$ confidence intervals represent mean baseline performance and rate of decline for the poor group. For the intermediate and optimal group, coefficients represent intercept differences and differences in rate of change compared to the poor group
cour

\begin{tabular}{|c|c|c|c|c|c|c|c|}
\hline & & \multicolumn{3}{|c|}{ Young-old $(60-72 \mathrm{y})$} & \multicolumn{3}{|c|}{ Old-old $(\geq 78 y)$} \\
\hline & & poor & intermediate & optimal & poor & intermediate & optimal \\
\hline \multicolumn{8}{|l|}{ Smoking $(n=1,950)$} \\
\hline \multirow[t]{2}{*}{ episodic memory } & level & $-0.21[-0.32,-0.10]$ & $-0.03[-0.22,0.17]$ & $0.06[-0.06,0.17]$ & $-0.31[-0.54,-0.08]$ & $-0.10[-0.51,0.31]$ & $0.16[-0.06,0.39]$ \\
\hline & change & $-0.05[-0.06,-0.03]$ & $0.04[0.01,0.06]^{* *}$ & $0.02[0.00,0.03]^{*}$ & $-0.03[-0.08,0.02]$ & $-0.10[-0.19,-0.01]^{*}$ & $-0.04[-0.09,0.01]$ \\
\hline \multirow[t]{2}{*}{ semantic memory } & level & $-0.03[-0.15,0.06]$ & $0.14[-0.09,0.36]$ & $-0.06[-0.20,0.07]$ & $0.18[-0.21,0.21]$ & $-0.22[-0.67,0.24]$ & $-0.26[-0.51,-0.01]^{*}$ \\
\hline & change & $-0.02[-0.03,-0.01]$ & $-0.01[-0.03,0.00]$ & $0.00[-0.01,0.01]$ & $-0.06[-0.10,-0.02]$ & $-0.09[-0.17,-0.02]^{*}$ & $0.00[-0.04,0.04]$ \\
\hline \multirow[t]{2}{*}{ verbal fluency } & level & $-0.04[-0.15,0.06]$ & $0.06[-0.12,0.24]$ & $-0.03[-0.13,0.08]$ & $0.00[-0.21,0.21]$ & $-0.27[-0.65,0.10]$ & $-0.07[-0.27,0.14]$ \\
\hline & change & $-0.03[-0.04,-0.02]$ & $0.00[-0.01,0.02]$ & $0.01[0.00,0.02]$ & $-0.09[-0.12,-0.05]$ & $-0.01[-0.08,0.05]$ & $0.01[-0.02,0.04]$ \\
\hline \multirow[t]{2}{*}{ perceptual speed } & level & $-0.27[-0.38,-0.16]$ & $0.23[0.04,0.42]^{*}$ & $0.27[0.16,0.38]^{* * *}$ & $-0.16[-0.41,0.09]$ & $-0.33[-0.77,0.11]$ & $0.10[-0.14,0.34]$ \\
\hline & change & $-0.06[-0.07,-0.05]$ & $0.01[-0.01,0.03]$ & $0.01[0.00,0.02]$ & $-0.11[-0.15,-0.06]$ & $-0.01[-0.09,0.07]$ & $0.00[-0.04,0.05]$ \\
\hline \multirow[t]{2}{*}{ global cognition } & level & $-0.13[-0.21,-0.05]$ & $0.10[-0.03,0.23]$ & $0.05[-0.02,0.13]$ & $-0.08[-0.25,0.08]$ & $-0.16[-0.45,0.14]$ & $0.00[-0.16,0.16]$ \\
\hline & change & $-0.04[-0.05,-0.04]$ & $0.01[0.00,0.02]$ & $0.01[0.00,0.02]^{* *}$ & $-0.07[-0.10,-0.04]$ & $-0.05[-0.11,0.00]$ & $0.00[-0.04,0.03]$ \\
\hline \multicolumn{8}{|l|}{ Diet $(n=1,879)$} \\
\hline \multirow[t]{2}{*}{ episodic memory } & level & $-0.16[-0.25,-0.07]$ & $0.00[-0.09,0.10]$ & $-0.07[-0.22,0.08]$ & $-0.19[-0.36,-0.03]$ & $0.09[-0.07,0.25]$ & $-0.08[-0.30,0.14]$ \\
\hline & change & $-0.03[-0.04,-0.02]$ & $0.00[-0.02,0.01]$ & $0.00[-0.02,0.02]$ & $-0.07[-0.09,-0.04]$ & $0.00[-0.03,0.03]$ & $0.00[-0.04,0.04]$ \\
\hline \multirow[t]{2}{*}{ semantic memory } & level & $-0.16[-0.21,-0.04]$ & $0.17[0.06,0.29]^{* *}$ & $0.05[-0.12,0.23]$ & $0.01[-0.22,0.09]$ & $0.01[-0.16,0.18]$ & $-0.12[-0.36,0.12]$ \\
\hline & change & $-0.02[-0.03,-0.01]$ & $0.00[-0.01,0.01]$ & $0.00[-0.01,0.01]$ & $-0.05[-0.07,-0.03]$ & $-0.01[-0.04,0.01]$ & $-0.02[-0.05,0.02]$ \\
\hline \multirow[t]{2}{*}{ verbal fluency } & level & $-0.12[-0.21,-0.04]$ & $0.10[0.01,0.19]^{*}$ & $0.13[-0.01,0.27]$ & $-0.07[-0.22,0.09]$ & $0.05[-0.10,0.20]$ & $0.01[-0.19,0.22]$ \\
\hline & change & $-0.02[-0.03,-0.02]$ & $0.00[-0.01,0.01]$ & $-0.01[-0.02,0.00]$ & $-0.08[-0.10,-0.07]$ & $0.01[-0.01,0.03]$ & $0.01[-0.02,0.04]$ \\
\hline \multirow[t]{2}{*}{ perceptual speed } & level & $-0.10[-0.19,-0.01]$ & $0.08[-0.02,0.18]$ & $0.10[-0.05,0.25]$ & $-0.03[-0.21,0.15]$ & $-0.02[-0.19,0.16]$ & $-0.18[-0.42,0.05]$ \\
\hline & change & $-0.05[-0.05,-0.04]$ & $-0.01[-0.02,0.00]$ & $-0.01[-0.02,0.01]$ & $-0.11[-0.14,-0.09]$ & $0.01[-0.01,0.04]$ & $0.01[-0.02,0.05]$ \\
\hline \multirow[t]{2}{*}{ global cognition } & level & $-0.13[-0.19,-0.07]$ & $0.09[0.02,0.16]^{* *}$ & $0.05[-0.05,0.15]$ & $-0.05[-0.17,0.07]$ & $0.03[-0.09,0.14]$ & $-0.11[-0.27,0.04]$ \\
\hline & change & $-0.03[-0.04,-0.03]$ & $0.00[-0.01,0.00]$ & $0.00[-0.01,0.01]$ & $-0.08[-0.10,-0.07]$ & $0.00[-0.02,0.02]$ & $0.00[-0.02,0.03]$ \\
\hline \multicolumn{8}{|c|}{ Physical activity $(n=1,929)$} \\
\hline \multirow[t]{2}{*}{ episodic memory } & level & $-0.11[-0.23,0.00]$ & $-0.05[-0.17,0.08]$ & $-0.11[-0.24,0.02]$ & $-0.34[-0.50,-0.18]$ & $0.22[0.06,0.37]^{* *}$ & $0.31[0.11,0.51]^{* *}$ \\
\hline & change & $-0.04[-0.06,-0.03]$ & $0.01[0.00,0.03]$ & $0.02[0.00,0.03]^{*}$ & $-0.04[-0.07,-0.02]$ & $-0.03[-0.06,0.00]$ & $-0.02[-0.06,0.01]$ \\
\hline \multirow[t]{2}{*}{ semantic memory } & level & $-0.09[-0.30,-0.09]$ & $0.09[-0.06,0.23]$ & $-0.05[-0.20,0.10]$ & $-0.15[-0.40,-0.10]$ & $0.14[-0.04,0.31]$ & $0.05[-0.19,0.28]$ \\
\hline & change & $-0.02[-0.03,-0.01]$ & $0.00[-0.01,0.01]$ & $-0.01[-0.02,0.01]$ & $-0.07[-0.09,-0.05]$ & $0.01[-0.01,0.04]$ & $0.01[-0.02,0.04]$ \\
\hline \multirow[t]{2}{*}{ verbal fluency } & level & $-0.19[-0.30,-0.09]$ & $0.16[0.04,0.27]^{* *}$ & $0.18[0.06,0.30]^{* *}$ & $-0.25[-0.40,-0.10]$ & $0.23[0.08,0.37]^{* *}$ & $0.25[0.06,0.44]^{* *}$ \\
\hline & change & $-0.02[-0.03,-0.01]$ & $-0.01[-0.02,0.00]^{*}$ & $-0.01[-0.02,0.00]$ & $-0.08[-0.09,-0.06]$ & $0.00[-0.03,0.02]$ & $0.01[-0.01,0.04]$ \\
\hline \multirow[t]{2}{*}{ perceptual speed } & level & $-0.19[-0.30,-0.08]$ & $0.13[0.01,0.26]^{*}$ & $0.23[0.10,0.36]^{* * *}$ & $-0.24[-0.42,-0.07]$ & $0.17[0.01,0.34]^{*}$ & $0.26[0.04,0.48]^{*}$ \\
\hline & change & $-0.05[-0.06,-0.04]$ & $0.00[-0.01,0.01]$ & $0.00[-0.02,0.01]$ & $-0.09[-0.12,-0.07]$ & $-0.02[-0.05,0.01]$ & $0.00[-0.03,0.04]$ \\
\hline \multirow[t]{2}{*}{ global cognition } & level & $-0.14[-0.22,-0.06]$ & $0.08[0.00,0.17]$ & $0.06[-0.03,0.15]$ & $-0.24[-0.35,-0.12]$ & $0.19[0.07,0.30]^{* *}$ & $0.22[0.07,0.37]^{* *}$ \\
\hline & change & $-0.03[-0.04,-0.03]$ & $0.00[-0.01,0.01]$ & $0.00[-0.01,0.01]$ & $-0.07[-0.09,-0.05]$ & $-0.01[-0.03,0.01]$ & $0.00[-0.03,0.02]$ \\
\hline \multicolumn{8}{|c|}{ Body mass index $(n=1,948)$} \\
\hline \multirow[t]{2}{*}{ episodic memory } & level & $-0.14[-0.26,-0.02]$ & $-0.03[-0.16,0.10]$ & $-0.06[-0.19,0.07]$ & $-0.20[-0.40,-0.01]$ & $0.06[-0.14,0.26]$ & $0.03[-0.17,0.22]$ \\
\hline & change & $-0.04[-0.05,-0.02]$ & $0.01[-0.01,0.02]$ & $0.01[-0.01,0.02]$ & $-0.03[-0.06,0.00]$ & $-0.04[-0.07,0.00]^{*}$ & $-0.04[-0.08,-0.01]^{*}$ \\
\hline semantic memory & level & $-0.21[-0.23,0.00]$ & $0.19[0.04,0.33]^{*}$ & $0.17[0.02,0.32]^{*}$ & $0.06[-0.29,0.07]$ & $-0.11[-0.34,0.12]$ & $-0.17[-0.39,0.06]$ \\
\hline & change & $-0.03[-0.04,-0.02]$ & $0.00[-0.01,0.01]$ & $0.01[0.00,0.02]$ & $-0.06[-0.09,-0.04]$ & $0.00[-0.03,0.03]$ & $0.00[-0.03,0.03]$ \\
\hline verbal fluency & level & $-0.11[-0.23,0.00]$ & $0.06[-0.06,0.18]$ & $0.08[-0.04,0.20]$ & $-0.11[-0.29,0.07]$ & $0.12[-0.07,0.31]$ & $-0.02[-0.20,0.17]$ \\
\hline & change & $-0.03[-0.04,-0.02]$ & $0.00[-0.01,0.01]$ & $0.01[0.00,0.02]$ & $-0.06[-0.08,-0.03]$ & $-0.03[-0.05,0.00]^{*}$ & $-0.02[-0.05,0.00]$ \\
\hline perceptual speed & level & $-0.22[-0.34,-0.11]$ & $0.21[0.08,0.34]^{* *}$ & $0.19[0.07,0.32]^{* *}$ & $-0.08[-0.29,0.12]$ & $0.03[-0.19,0.24]$ & $-0.04[-0.25,0.18]$ \\
\hline & change & $-0.05[-0.06,-0.04]$ & $0.00[-0.01,0.01]$ & $0.00[-0.01,0.01]$ & $-0.09[-0.12,-0.07]$ & $-0.01[-0.04,0.02]$ & $-0.01[-0.04,0.02]$ \\
\hline global cognition & level & $-0.17[-0.25,-0.08]$ & $0.10[0.01,0.19]^{*}$ & $0.09[0.00,0.18]^{*}$ & $-0.09[-0.23,0.05]$ & $0.04[-0.11,0.18]$ & $-0.03[-0.18,0.11]$ \\
\hline & change & $-0.04[-0.04,-0.03]$ & $0.00[-0.01,0.01]$ & $0.01[0.00,0.01]$ & $-0.06[-0.08,-0.04]$ & $-0.02[-0.04,0.00]$ & $-0.03[-0.05,0.00]^{*}$ \\
\hline
\end{tabular}


Table 5

(Continued)

\begin{tabular}{|c|c|c|c|c|c|c|c|}
\hline & & \multicolumn{3}{|c|}{ Young-old $(60-72 \mathrm{y})$} & \multicolumn{3}{|c|}{ Old-old ( $\geq 78 \mathrm{y})$} \\
\hline & & poor & intermediate & optimal & poor & intermediate & optimal \\
\hline \multicolumn{8}{|c|}{ Plasma glucose $(n=1,950)$} \\
\hline \multirow[t]{2}{*}{ episodic memory } & level & $-0.11[-0.26,0.05]$ & $-0.10[-0.27,0.08]$ & $-0.06[-0.23,0.11]$ & $-0.06[-0.28,0.17]$ & $-0.09[-0.33,0.14]$ & $-0.14[-0.37,0.08]$ \\
\hline & change & $-0.05[-0.07,-0.03]$ & $0.02[0.00,0.05]$ & $0.02[0.00,0.04]$ & $-0.04[-0.07,0.00]$ & $-0.05[-0.09,0.00]^{*}$ & $-0.03[-0.07,0.01]$ \\
\hline \multirow[t]{2}{*}{ semantic memory } & level & $-0.17[-0.35,-0.06]$ & $0.09[-0.11,0.30]$ & $0.13[-0.06,0.33]$ & $-0.18[-0.35,0.06]$ & $0.11[-0.15,0.37]$ & $0.16[-0.09,0.41]$ \\
\hline & change & $-0.04[-0.06,-0.03]$ & $0.02[0.01,0.04]^{* *}$ & $0.02[0.01,0.04]^{* *}$ & $-0.04[-0.07,-0.01]$ & $-0.02[-0.06,0.01]$ & $-0.02[-0.06,0.01]$ \\
\hline \multirow[t]{2}{*}{ verbal fluency } & level & $-0.21[-0.35,-0.06]$ & $0.16[0.00,0.32]$ & $0.17[0.02,0.33]^{*}$ & $-0.14[-0.35,0.06]$ & $0.12[-0.09,0.33]$ & $0.06[-0.15,0.26]$ \\
\hline & change & $-0.04[-0.06,-0.03]$ & $0.01[0.00,0.03]$ & $0.02[0.01,0.03]^{* *}$ & $-0.07[-0.10,-0.04]$ & $-0.02[-0.05,0.02]$ & $0.00[-0.03,0.03]$ \\
\hline \multirow[t]{2}{*}{ perceptual speed } & level & $-0.28[-0.44,-0.13]$ & $0.23[0.05,0.40]^{*}$ & $0.29[0.12,0.45]^{* *}$ & $-0.24[-0.49,0.00]$ & $0.16[-0.09,0.41]$ & $0.17[-0.07,0.41]$ \\
\hline & change & $-0.08[-0.09,-0.06]$ & $0.02[0.00,0.04]^{*}$ & $0.02[0.01,0.04]^{* *}$ & $-0.06[-0.10,-0.03]$ & $-0.04[-0.08,-0.01]^{*}$ & $-0.04[-0.08,0.00]^{*}$ \\
\hline \multirow[t]{2}{*}{ global cognition } & level & $-0.19[-0.30,-0.08]$ & $0.10[-0.03,0.22]$ & $0.13[0.02,0.25]^{*}$ & $-0.13[-0.30,0.03]$ & $0.06[-0.11,0.22]$ & $0.05[-0.12,0.21]$ \\
\hline & change & $-0.05[-0.06,-0.04]$ & $0.02[0.01,0.03]^{* *}$ & $0.02[0.01,0.03]^{* * *}$ & $-0.05[-0.08,-0.03]$ & $-0.03[-0.06,-0.01]^{*}$ & $-0.02[-0.05,0.00]$ \\
\hline \multicolumn{8}{|c|}{ Total serum cholesterol $(n=1,941)$} \\
\hline \multirow[t]{2}{*}{ episodic memory } & level & $-0.17[-0.26,-0.09]$ & $0.01[-0.09,0.10]$ & $0.03[-0.12,0.17]$ & $-0.15[-0.29,-0.01]$ & $0.01[-0.13,0.15]$ & $-0.11[-0.30,0.08]$ \\
\hline & change & $-0.02[-0.03,-0.02]$ & $-0.01[-0.02,0.00]^{*}$ & $-0.01[-0.02,0.01]$ & $-0.07[-0.09,-0.05]$ & $0.00[-0.02,0.03]$ & $0.00[-0.04,0.03]$ \\
\hline \multirow[t]{2}{*}{ semantic memory } & level & $-0.03[-0.12,0.04]$ & $-0.08[-0.19,0.03]$ & $0.01[-0.15,0.17]$ & $0.07[-0.11,0.16]$ & $-0.20[-0.35,-0.04]^{*}$ & $-0.14[-0.35,0.08]$ \\
\hline & change & $-0.02[-0.02,-0.01]$ & $0.00[-0.01,0.01]$ & $-0.01[-0.02,0.01]$ & $-0.07[-0.08,-0.05]$ & $0.01[-0.01,0.03]$ & $0.00[-0.03,0.03]$ \\
\hline \multirow[t]{2}{*}{ verbal fluency } & level & $-0.04[-0.12,0.04]$ & $-0.04[-0.13,0.04]$ & $0.00[-0.13,0.13]$ & $0.02[-0.11,0.16]$ & $-0.15[-0.28,-0.02]^{*}$ & $-0.11[-0.29,0.06]$ \\
\hline & change & $-0.02[-0.03,-0.02]$ & $-0.01[-0.01,0.00]$ & $-0.01[-0.02,0.00]$ & $-0.07[-0.09,-0.06]$ & $0.00[-0.02,0.02]$ & $-0.01[-0.04,0.01]$ \\
\hline \multirow[t]{2}{*}{ perceptual speed } & level & $-0.05[-0.14,0.03]$ & $0.00[-0.09,0.09]$ & $-0.01[-0.15,0.13]$ & $-0.04[-0.19,0.11]$ & $-0.05[-0.19,0.10]$ & $-0.11[-0.32,0.09]$ \\
\hline & change & $-0.05[-0.06,-0.04]$ & $-0.01[-0.02,0.00]$ & $-0.01[-0.02,0.01]$ & $-0.09[-0.11,-0.08]$ & $-0.01[-0.03,0.01]$ & $-0.03[-0.06,0.00]$ \\
\hline \multirow[t]{2}{*}{ global cognition } & level & $-0.07[-0.13,-0.01]$ & $-0.03[-0.09,0.04]$ & $0.01[-0.09,0.10]$ & $-0.02[-0.12,0.09]$ & $-0.10[-0.20,0.00]$ & $-0.12[-0.26,0.01]$ \\
\hline & change & $-0.03[-0.03,-0.03]$ & $-0.01[-0.01,0.00]^{*}$ & $-0.01[-0.01,0.00]$ & $-0.08[-0.09,-0.07]$ & $0.00[-0.01,0.02]$ & $-0.01[-0.03,0.01]$ \\
\hline \multicolumn{8}{|c|}{ Blood pressure $(n=1,941)$} \\
\hline \multirow[t]{2}{*}{ episodic memory } & level & $-0.16[-0.24,-0.09]$ & $-0.03[-0.12,0.07]$ & $0.03[-0.14,0.20]$ & $-0.15[-0.26,-0.04]$ & $-0.04[-0.19,0.11]$ & $-0.18[-0.56,0.20]$ \\
\hline & change & $-0.03[-0.04,-0.03]$ & $0.01[0.00,0.02]$ & $0.00[-0.02,0.02]$ & $-0.06[-0.08,-0.05]$ & $-0.01[-0.03,0.02]$ & $-0.04[-0.11,0.03]$ \\
\hline \multirow[t]{2}{*}{ semantic memory } & level & $-0.08[-0.14,0.00]$ & $0.07[-0.04,0.18]$ & $-0.08[-0.28,0.12]$ & $-0.07[-0.14,0.07]$ & $0.00[-0.17,0.17]$ & $0.44[0.01,0.86]^{*}$ \\
\hline & change & $-0.02[-0.03,-0.02]$ & $0.00[0.00,0.01]$ & $0.01[-0.01,0.02]$ & $-0.06[-0.07,-0.05]$ & $0.00[-0.03,0.02]$ & $0.00[-0.06,0.06]$ \\
\hline \multirow[t]{2}{*}{ verbal fluency } & level & $-0.07[-0.14,0.00]$ & $0.02[-0.06,0.11]$ & $0.02[-0.14,0.18]$ & $-0.03[-0.14,0.07]$ & $-0.14[-0.27,0.00]$ & $0.05[-0.29,0.40]$ \\
\hline & change & $-0.03[-0.03,-0.02]$ & $0.01[0.00,0.01]$ & $0.00[-0.01,0.02]$ & $-0.07[-0.08,-0.06]$ & $-0.01[-0.03,0.01]$ & $-0.03[-0.08,0.02]$ \\
\hline \multirow[t]{2}{*}{ perceptual speed } & level & $-0.08[-0.15,-0.01]$ & $0.06[-0.03,0.15]$ & $0.11[-0.06,0.28]$ & $-0.07[-0.20,0.05]$ & $-0.08[-0.24,0.08]$ & $0.13[-0.27,0.53]$ \\
\hline & change & $-0.06[-0.06,-0.05]$ & $0.00[-0.01,0.01]$ & $0.01[0.00,0.03]^{*}$ & $-0.10[-0.11,-0.08]$ & $-0.02[-0.05,0.01]$ & $-0.03[-0.10,0.03]$ \\
\hline \multirow[t]{2}{*}{ global cognition } & level & $-0.10[-0.15,-0.04]$ & $0.03[-0.03,0.10]$ & $0.02[-0.09,0.14]$ & $-0.08[-0.16,0.01]$ & $-0.06[-0.17,0.05]$ & $0.10[-0.17,0.37]$ \\
\hline & change & $-0.04[-0.04,-0.03]$ & $0.01[0.00,0.01]$ & $0.01[0.00,0.02]$ & $-0.08[-0.09,-0.07]$ & $-0.01[-0.03,0.01]$ & $-0.02[-0.07,0.02]$ \\
\hline
\end{tabular}


group, is relatively good. Smoking was the metric with the highest proportion of individuals in the optimal group $(79.1 \%)$. This is consistent with several other studies, reporting a range from $47 \%$ to $84 \%$ of participants satisfying optimal criteria for smoking [29-31]. Blood pressure was the metrics with the smallest proportion of individuals in the optimal group, especially for the old-old. Other studies have reported similar prevalence $[14,32]$, as well as large age differences regarding the proportion of individuals in the optimal blood pressure group [33].

\section{Total LS7 score}

Adherence to the LS7 recommendations has been linked to lower risk of stroke and heart failure [29, 30], fewer incident cardiovascular events [34], and lower mortality $[35,36]$. Better cardiovascular health scores have further been associated with lower risk of incident cognitive impairment [19] and dementia [16]. With regard to cognition, a cross-sectional study observed an association between the LS7 total score and 7 out of 8 measures of cognitive performance. Similarly, a higher number of ideal LS7 metrics was associated with better global cognition [28].

Only a few studies have explored the association between LS7 and rate of cognitive change. In one study, midlife cardiovascular health was associated with better global cognition and slower cognitive decline across 20 years [15]. A study by Gardener et al. [14], where the sample mean age was similar to ours, reported that number of ideal LS7 metrics was associated with slower decline in processing speed and, to a lesser extent, episodic memory and executive function across 6 years of follow-up. In this study, we found the strongest associations for perceptual speed. This finding fits well with the cross-sectional findings by Gardener et al. although, in contrast to that study, we did not observe any association between the LS7 total score and rate of perceptual speed decline.

An additional aim of our study was to examine potentially different patterns for younger and older age groups. LS7 has so far mostly been applied to midlife populations, either exploring the link with dementia [16, 32, 37] or cognition [15, 19, 38]. However, Samieri et al. [39] examined the associations of LS7 with cognitive decline and incident dementia in an older sample (mean age $=73.7$ years). They found that a higher number of metrics at optimal levels and a higher total LS7 score were related to a slower rate of decline in global cognition and memory. The lack of findings for the total sample for rate of cognitive decline could partly be due to relatively low power in our study.

Importantly, however, when stratifying the sample by age, we observed different and sometimes opposite patterns for the young-old and old-old age groups. For the young-old, a higher LS7 total score was associated with slower decline in episodic memory and global cognition, similar to Samieri et al. For the old-old individuals, however, the effect was reversed (although not significant). Thus, all significant results in the total sample were driven by the young-old individuals. It is of interest to note that although the old-old sample in general evidenced a faster rate of cognitive decline, we cannot account for this accelerated decline with LS7. This may be due to 1) the cardiovascular health of the older age group being similar to that of the younger group, 2) the association between the LS7 score and cognition being weaker in the old-old age group.

The cognitive domain most consistently associated with the LS7 score was perceptual speed. Previous studies have shown that vascular risk factors may affect white matter integrity [40], which in turn has been associated with poorer perceptual speed performance [41, 42]. However, alterations in cerebral white matter have also been associated with poorer episodic memory and global cognition [43], which may explain our observation that a lower LS7 score was associated with faster decline in these domains.

\section{LS7 individual metrics}

Physical activity and diet were associated with the largest number of cognitive domains in terms of level. However, better scores in these metrics were not associated with slower rates of cognitive decline. For rate of change, the strongest associations were instead observed for blood pressure and plasma glucose.

Gardener et al. [14] reported that the association between optimal LS7 and decline in processing speed performance was mostly driven by smoking and glucose levels. These two metrics, together with BMI, were also strongly associated with incident cognitive impairment [19]. The relatively high proportion of individuals in the optimal group $(79.1 \%)$ could be a reason for the small effects of smoking in our study. In fact, belonging to the intermediate smoking group was associated with a faster rate of decline in semantic memory compared to the poor group. A possible explanation is that participants in the intermediate group (who stopped smoking in the last 5 years) quit smoking recently because of health problems and 
experienced faster cognitive decline because of general poor health. Consistent with Gardener et al. [14], we observed significant associations between plasma glucose levels and rates of cognitive decline. In addition, better blood pressure values were associated with slower decline in most cognitive domains.

A possible reason why biological health factors are more strongly associated with cognitive change is that ideal levels of health behaviors may be more unstable and harder to maintain over time [15]. Health behaviors are furthermore mostly assessed through self-reports and may therefore be less reliable.

Further examining individual LS7 metrics by the two age groups partly confirmed the pattern observed in the total sample. In general, there were more significant associations between LS7 and cognition in young-old, especially for plasma glucose and diet. For the old-old group, findings of significant associations were often in the opposite direction. Better levels of smoking, BMI, glucose, and cholesterol were associated with worse cognitive function. Relatedly, a recent study found that the association of ideal LS7 with a reduced dementia risk was mainly present at mid-life, which was explained by age-varying association between biological health factors and risk of dementia [37]. Similar age-differential patterns have also been observed for other vascular risk scores, such as the Framingham general cardiovascular risk score [44]. This is in line with past research suggesting that cross-sectional and longitudinal relations of some vascular risk factors to cognitive function change with age.

For example, lower cholesterol has been associated with slower cognitive decline in young old individuals, whereas the opposite was found among the old-old [45]. Other studies have also been reporting associations of higher cholesterol level with better cognitive performance [46, 47]. Different mechanistic hypotheses can explain this pattern. A low cholesterol score may reflect decline in cholesterol levels, which may be associated with early stages of dementia [48]. Because cholesterol is an indispensable component of myelin, neuronal membranes, and glial membranes, it is involved in both cerebral structure and function [49]. Low-normal cholesterol levels have been associated with poorer cognitive performance and reduced brain volume in regions implicated in neurodegenerative diseases [47].

Similarly, low blood pressure [50,51] and low BMI $[52,53]$ have been associated with poorer cognition in late life. A possible explanation is that a decrease in blood pressure and BMI could be linked to an impending dementia disorder $[54,55]$; thus, reverse causation may explain these findings. Low levels of BMI may also be a marker of frailty [56], making it a problematic indicator of obesity in the elderly. Furthermore, survival bias could contribute to our results, such that those who have survived into old age may be more resistant to the adverse effects of different vascular risk factors.

\section{Implications}

The results from our study add to previous findings suggesting that the associations between certain vascular risk factors and cognition may change between midlife and old age. By combining the LS7 metrics into a sum score, there is a risk that they cancel each other out, especially in older age groups. Different age patterns, observed for some LS7 metrics, may be one reason for the few significant associations between LS7 and cognitive decline in our total sample. We therefore conclude that the LS7 score may be more suitable for predicting cognitive trajectories in groups of middle-aged and young-old adults.

Our results further show a largely negligible difference between the intermediate and optimal groups and that it was sufficient to belong to the intermediate cardiovascular health group to exhibit slower decline. In line with this, the results from another longitudinal study suggest that having an ideal score on only a few LS7 metrics may be enough to experience cognitive health benefits [14]. We further found that excluding those with a history of cardiovascular disease at baseline attenuated the associations of LS7 with cognition, especially for plasma glucose. A possible explanation is that it takes time for a vascular risk factor to exert its influence of cognitive performance. At earlier stages, the association with cognition may not yet be apparent, but over time, and with an increasing burden of vascular insults, the effect on cognition becomes more evident. This underscores the importance of early identification and management of vascular risk factors.

\section{Strengths and limitations}

Strengths of this study include a population-based sample with a wide age range, that enables the comparison between a young-old and old-old group. The present study furthermore extends the results of prior studies by assessing decline in a wide range of cognitive domains across 12 years of follow-up. 
Some limitations should also be mentioned. All behavioral metrics, except BMI that was objectively measured for the majority of the participants, were obtained via self-reports, which are less reliable compared to objective measurements. A bias is that participants with poor scores on the biological health factors (cholesterol, plasma glucose, and blood pressure) were advised to contact their physician for further investigation, which may have affected their future cognitive trajectories. Moreover, exclusion due to missing data and selective dropout may have contributed to an overestimation of the cardiovascular health in this population, as well as an underestimation of the effect of LS7 on rate of cognitive change. Additional limitations are that we only measured LS7 at a single point in time and that we did not have access to LS7 scores at younger ages for the participants. Thus, we were not able to assess associations between cardiovascular health at midlife and latelife cognitive change. Nor were we able to address the potential association between change in LS7 and cognitive change trajectories.

It should also be emphasized that the effects of LS7 on cognitive performance were relatively small and that it is one of several factors that contribute to cognitive decline in aging. Future studies should investigate to what extent assessment and management of vascular risk factors at midlife may help promote brain health and maintain cognitive abilities into old age.

\section{ACKNOWLEDGMENTS}

We thank the participants as well as the staff involved in the data collection and management of the SNAC-K study. SNAC-K is financially supported by the Swedish Ministry of Health and Social Affairs, the participating County Councils and Municipalities, and the Swedish Research Council. This work was further funded by the Swedish Research Council (EL), the Fondation pour la Recherche sur Alzheimer (BW), Stiftelsen Dementia (AS), and by a donation from the af Jochnick Foundation (LB).

Authors' disclosures available online (https:// www.j-alz.com/manuscript-disclosures/21-0280r4).

\section{SUPPLEMENTARY MATERIAL}

The supplementary material is available in the electronic version of this article: https://dx.doi.org/ $10.3233 / \mathrm{JAD}-210280$.

\section{REFERENCES}

[1] Duron E, Hanon O (2008) Vascular risk factors, cognitive decline, and dementia. Vasc Health Risk Manag 4, 363-381.

[2] De La Torre JC (2002) Alzheimer disease as a vascular disorder nosological evidence. Stroke 33, 1152-1162.

[3] Marseglia A, Fratiglioni L, Laukka EJ, Santoni G, Pedersen NL, Bäckman L, Xu W (2016) Early cognitive deficits in type 2 diabetes: A population-based study. J Alzheimers Dis 53, 1069-1078.

[4] Secnik J, Schwertner E, Alvarsson M, Hammar N, Fastbom J, Winblad B, Garcia-Ptacek S, Religa D, Eriksdotter M (2020) Cholinesterase inhibitors in patients with diabetes mellitus and dementia: An open-cohort study of $\sim 23000$ patients from the Swedish Dementia Registry. BMJ Open Diabetes Res Care 8, e000833.

[5] Shakersain B, Rizzuto D, Larsson SC, Faxén-Irving G, Fratiglioni L, Xu WL (2018) The Nordic prudent diet reduces risk of cognitive decline in the Swedish older adults: A population- based cohort study. Nutrients 10, 229.

[6] Richards M, Jarvis MJ, Thompson N, Wadsworth MEJ (2003) Cigarette smoking and cognitive decline in midlife: Evidence from a prospective birth cohort study. Am J Public Health 93, 994-998.

[7] Guure CB, Ibrahim NA, Adam MB, Said SM (2017) Impact of physical activity on cognitive decline, dementia, and its subtypes: Meta-analysis of prospective studies. Biomed Res Int 2017, 9016924.

[8] Gottesman RF, Schneider ALC, Albert M, Alonso A, Bandeen-Roche K, Coker L, Coresh J, Knopman D, Power MC, Rawlings A, Sharrett AR, Wruck LM, Mosley TH (2014) Midlife hypertension and 20-year cognitive change: The atherosclerosis risk in communities neurocognitive study. JAMA Neurol 71, 1218-1227.

[9] Elias PK, Elias MF, Robbins MA, Budge MM (2004) Blood pressure-related cognitive decline: Does age make a difference? Hypertension 44, 631-636.

[10] Dregan A, Stewart R, Gulliford MC (2013) Cardiovascular risk factors and cognitive decline in adults aged 50 and over: A population-based cohort study. Age Ageing 42, 338-345.

[11] Fortin M, Bravo G, Hudon C, Vanasse A, Lapointe L (2005) Prevalence of multimorbidity among adults seen in family practice. Ann Fam Med 3, 223-228.

[12] Ngandu T, Lehtisalo J, Solomon A, Levälahti E, Ahtiluoto S, Antikainen R, Bäckman L, Hänninen T, Jula A, Laatikainen T, Lindström J, Mangialasche F, Paajanen T, Pajala S, Peltonen M, Rauramaa R, Stigsdotter-Neely A, Strandberg T, Tuomilehto J, Soininen H, Kivipelto M (2015) A 2 year multidomain intervention of diet, exercise, cognitive training, and vascular risk monitoring versus control to prevent cognitive decline in at-risk elderly people (FINGER): A randomised controlled trial. Lancet 385, 2255-2263.

[13] Lloyd-Jones DM, Hong Y, Labarthe D, Mozaffarian D, Appel LJ, Van Horn L, Greenlund K, Daniels S, Nichol G, Tomaselli GF, Arnett DK, Fonarow GC, Ho PM, Lauer MS, Masoudi FA, Robertson RM, Roger V, Schwamm LH, Sorlie P, Yancy CW, Rosamond WD (2010) Defining and setting national goals for cardiovascular health promotion and disease reduction: The American Heart Association's strategic impact goal through 2020 and beyond. Circulation 121, 586-613.

[14] Gardener H, Wright CB, Dong C, Cheung K, DeRosa J, Nannery M, Stern Y, Elkind MSV, Sacco RL (2016) Ideal cardiovascular health and cognitive aging in the Northern Manhattan. J Am Heart Assoc 5, e002731. 
[15] González HM, Tarraf W, Harrison K, Windham BG, Tingle J, Alonso A, Griswold M, Heiss G, Knopman D, Mosley TH (2018) Midlife cardiovascular health and 20-year cognitive decline: Atherosclerosis Risk in Communities Study results. Alzheimers Dement 14, 579-589.

[16] Sabia S, Fayosse A, Dumurgier J, Schnitzler A, Empana JP, Ebmeier KP, Dugravot A, Kivimäki M, Singh-Manoux A (2019) Association of ideal cardiovascular health at age 50 with incidence of dementia: 25 Year follow-up of Whitehall II cohort study. BMJ 366, 14414.

[17] Johansson I, Hallmans G, Wikman A, Biessy C, Riboli E, Kaaks R (2002) Validation and calibration of foodfrequency questionnaire measurements in the Northern Sweden Health and Disease cohort. Public Health Nutr $\mathbf{5}$, 487-496.

[18] Rugge B, Balshem H, Sehgal R, Relevo R, Forman P, Helfand M (2011) Screening and Treatment of Subclinical Hypothyroidism or Hyperthyroidism, Agency for Healthcare Research and Quality, Rockville.

[19] Thacker EL, Gillett SR, Wadley VG, Unverzagt FW, Judd SE, McClure LA, Howard VJ, Cushman M (2014) The American Heart Association life's simple 7 and incident cognitive impairment: The REasons for Geographic And Racial Differences in Stroke (REGARDS) study. J Am Heart Assoc 3, e000635.

[20] Laukka EJ, Köhncke Y, Papenberg G, Fratiglioni L, Bäckman L (2020) Combined genetic influences on episodic memory decline in older adults without dementia. $\mathrm{Neu}$ ropsychology 34, 654-666.

[21] Laukka EJ, Lövdén M, Herlitz A, Karlsson S, Ferencz B, Pantzar A, Keller L, Graff C, Fratiglioni L, Bäckman L (2013) Genetic effects on old-age cognitive functioning: A population-based study. Psychol Aging 28, 262-274.

[22] Nilsson LG, Bäckman L, Erngrund K, Nyberg L, Adolfsson R, Bucht G, Karlsson S, Widing M, Winblad B (1997) The Betula prospective cohort study: Memory, health, and aging. Aging Neuropsychol Cogn 4, 1-32.

[23] Lezak MD (2004) Neuropsychological Assessment, Oxford University Press, USA.

[24] Zazzo R (1974) Test des deux barrages. Actualités pédagogiques et psychologiques, Delachaux et Nestle, Neuchatel, Switzerland.

[25] Salthouse TA, Babcock RL (1991) Decomposing adult age differences in working memory. Dev Psychol 27, 763-776.

[26] Calderón-Larrañaga A, Vetrano DL, Onder G, GimenoFeliu LA, Coscollar-Santaliestra C, Carfí A, Pisciotta MS, Angleman S, Melis RJF, Santoni G, Mangialasche F, Rizzuto D, Welmer AK, Bernabei R, Prados-Torres A, Marengoni A, Fratiglioni L (2017) Assessing and measuring chronic multimorbidity in the older population: A proposal for its operationalization. J Gerontol A Biol Sci Med Sci 72, 1417-1423.

[27] Shang Y, Fratiglioni L, Marseglia A, Plym A, Welmer AK, Wang HX, Wang R, Xu W (2020) Association of diabetes with stroke and post-stroke dementia: A population-based cohort study. Alzheimers Dement 16, 1003-1012.

[28] Crichton GE, Elias MF, Davey A, Alkerwi A (2014) Cardiovascular health and cognitive function: The Maine-Syracuse Longitudinal Study. PLoS One 9, e89317.

[29] Folsom AR, Shah AM, Lutsey PL, Roetker NS, Alonso A, Avery CL, Miedema MD, Konety S, Chang PP, Solomon SD (2015) American Heart Association's Life's Simple 7: Avoiding heart failure and preserving cardiac structure and function. Am J Med 128, 970-976.
[30] Kulshreshtha A, Vaccarino V, Judd SE, Howard VJ, McClellan WM, Muntner P, Hong Y, Safford MM, Goyal A, Cushman M (2013) Life's Simple 7 and risk of incident stroke: The reasons for geographic and racial differences in stroke study. Stroke 44, 1909-1914.

[31] Bambs C, Kip KE, Dinga A, Mulukutla SR, Aiyer AN, Reis SE (2011) Low prevalence of ideal cardiovascular health in a community-based population: The heart strategies concentrating on risk evaluation (Heart SCORE) study. Circulation 123, 850-857.

[32] Hessler JB, Ander KH, Brönner M, Etgen T, Förstl H, Poppert H, Sander D, Bickel H (2016) Predicting dementia in primary care patients with a cardiovascular health metric: A prospective population-based study. BMC Neurol 16, 116.

[33] Lee VWY, Fong FYH, Cheng FWT, Yan BPY (2019) Life's Simple 7 and cardiovascular disease risk knowledge in Hong Kong. BMC Cardiovasc Disord 19, 185.

[34] Folsom AR, Yatsuya H, Nettleton JA, Lutsey PL, Cushman M, Rosamond WD (2011) Community prevalence of ideal cardiovascular health, by the American Heart Association definition, and relationship with cardiovascular disease incidence. J Am Coll Cardiol 57, 1690-1696.

[35] Lin MP, Ovbiagele B, Markovic D, Towfighi A (2015) "Life's Simple 7" and long-term mortality after stroke. $J$ Am Heart Assoc 4, e001470.

[36] Yang Q, Cogswell ME, Dana Flanders W, Hong Y, Zhang Z, Loustalot F, Gillespie C, Merritt R, Hu FB (2012) Trends in cardiovascular health metrics and associations with allcause and CVD mortality among us adults. JAMA 307, 12731283.

[37] Liang Y, Ngandu T, Laatikainen T, Soininen H, Tuomilehto J, Kivipelto M, Qiu C (2020) Cardiovascular health metrics from mid- to late-life and risk of dementia: A populationbased cohort study in Finland. PLoS Med 17, e1003474.

[38] Reis JP, Loria CM, Launer LJ, Sidney S, Liu K, Jacobs DR, Zhu N, Lloyd-Jones DM, He K, Yaffe K (2013) Cardiovascular health through young adulthood and cognitive functioning in midlife. Ann Neurol 73, 170-179.

[39] Samieri C, Perier MC, Gaye B, Proust-Lima C, Helmer C, Dartigues JF, Berr C, Tzourio C, Empana JP (2018) Association of cardiovascular health level in older age with cognitive decline and incident dementia. JAMA 320, 657-664.

[40] Power MC, Tingle JV, Reid RI, Huang J, Sharrett AR, Coresh J, Griswold M, Kantarci K, Jack CR, Knopman D, Gottesman RF, Mosley TH (2017) Midlife and latelife vascular risk factors and white matter microstructural integrity: The atherosclerosis risk in communities neurocognitive study. J Am Heart Assoc 6, e005608.

[41] Laukka EJ, Lövdén M, Kalpouzos G, Li TQ, Jonsson T, Wahlund LO, Fratiglioni L, Bäckman L (2013) Associations between white matter microstructure and cognitive performance in old and very old age. PLoS One 8, e81419.

[42] Oschwald J, Mérillat S, Liem F, Röcke C, Martin M, Jäncke L (2019) Lagged coupled changes between white matter microstructure and processing speed in healthy aging: A longitudinal investigation. Front Aging Neurosci 11, 298.

[43] Kloppenborg RP, Nederkoorn PJ, Geerlings MI, Van Den Berg E (2014) Presence and progression of white matter hyperintensities and cognition: A meta-analysis. Neurology 82, 2127-2138.

[44] Wang R, Fratiglioni L, Kalpouzos G, Lövdén M, Laukka EJ, Bronge L, Wahlund LO, Bäckman L, Qiu C (2017) Mixed brain lesions mediate the association between cardiovascular risk burden and cognitive decline in old age: A population-based study. Alzheimers Dement 13, 247-256. 
[45] Wendell CR, Waldstein SR, Zonderman AB (2014) Nonlinear longitudinal trajectories of cholesterol and neuropsychological function. Neuropsychology 28, 106-112.

[46] Zhou F, Deng W, Ding D, Zhao Q, Liang X, Wang F, Luo J, Zheng L, Guo Q, Hong Z (2018) High low-density lipoprotein cholesterol inversely relates to dementia in community-dwelling older adults: The Shanghai Aging study. Front Neurol 9, 952.

[47] Yang FN, Stanford M, Jiang X (2020) Low cholesterol level linked to reduced semantic fluency performance and reduced gray matter volume in the medial temporal lobe. Front Aging Neurosci 12, 57.

[48] Stewart R, White LR, Xue QL, Launer LJ (2007) Twentysix-year change in total cholesterol levels and incident dementia: The Honolulu-Asia aging study. Arch Neurol 64, 103-107.

[49] Pfrieger FW, Ungerer N (2011) Cholesterol metabolism in neurons and astrocytes. Prog Lipid Res 50, 357-371.

[50] Waldstein SR, Giggey PP, Thayer JF, Zonderman AB (2005) Nonlinear relations of blood pressure to cognitive function: The Baltimore longitudinal study of aging. Hypertension 45, 374-379.

[51] Qiu C, Winblad B, Fratiglioni L (2005) The age-dependent relation of blood pressure to cognitive function and dementia. Lancet Neurol 4, 487-499.
[52] Arvanitakis Z, Capuano AW, Bennett DA, Barnes LL (2018) Body mass index and decline in cognitive function in older black and white persons. J Gerontol A Biol Sci Med Sci 73, 198-203.

[53] Suemoto CK, Gilsanz P, Mayeda ER, Glymour MM (2015) Body mass index and cognitive function: The potential for reverse causation. Int J Obes 39, 1383-1389.

[54] Kivimäki M, Luukkonen R, Batty GD, Ferrie JE, Pentti J, Nyberg ST, Shipley MJ, Alfredsson L, Fransson EI, Goldberg M, Knutsson A, Koskenvuo M, Kuosma E, Nordin M, Suominen SB, Theorell T, Vuoksimaa E, Westerholm P, Westerlund H, Zins M, Kivipelto M, Vahtera J, Kaprio J, Singh-Manoux A, Jokela M (2018) Body mass index and risk of dementia: Analysis of individual-level data from 1.3 million individuals. Alzheimers Dement 14, 601-609.

[55] Nilsson SE, Read S, Berg S, Johansson B, Melander A, Lindblad U (2007) Low systolic blood pressure is associated with impaired cognitive function in the oldest old: Longitudinal observations in a population-based sample 80 years and older. Aging Clin Exp Res 19, 41-47.

[56] Rietman ML, van der a DL, van Oostrom SH, Picavet HSJ, Dollé MET, van Steeg H, Verschuren WMM, Spijkerman AMW (2018) The association between BMI and different frailty domains: A U-shaped curve? J Nutr Healths Aging 22, 8-15. 